\title{
Seed Oil of Morinda citrifolia L. as a Surfactant for Deinking Flotation
}

\author{
Trismawati Trismawati, I. N. G. Wardana, Nurkholis Hamidi, and Mega Nur Sasongko \\ Department of Mechanical Engineering, Brawijaya University, Malang 65144, Indonesia \\ Correspondence should be addressed to Trismawati Trismawati; trismawati@upm.ac.id
}

Received 16 January 2017; Revised 13 April 2017; Accepted 20 April 2017; Published 23 May 2017

Academic Editor: Bhaskar Kulkarni

Copyright (C) 2017 Trismawati Trismawati et al. This is an open access article distributed under the Creative Commons Attribution License, which permits unrestricted use, distribution, and reproduction in any medium, provided the original work is properly cited.

\begin{abstract}
Surfactants are essential in the pulp recovery process for the removal of ink on paper to be recycled. In order to create a "green" surfactant, seed oil was extracted from Morinda citrifolia L. by Soxhlet extraction for $4-8 \mathrm{~h}$ and its composition evaluated by gas chromatography-mass spectrometry (GC-MS). The total ion chromatogram (TIC) of fatty acids of Morinda citrifolia L. (FAMC) indicated that extraction yields the largest amount of unsaturated fatty acids (UFA), specifically $\mathrm{C}_{19} \mathrm{H}_{34} \mathrm{O}_{2}$ and $\mathrm{C}_{21} \mathrm{H}_{38} \mathrm{O}_{2}$, at 6 h. All FAMC fractions were evaluated for their suitability as a surfactant for deinking flotation. FAMC isolated after $6 \mathrm{~h}$ of extraction yields fatty acids that are the most suitable surfactants, as the fraction consists of mostly unsaturated fatty acids that show good interactions with the structure of common ink molecules. Our results show that the performance of the FAMC taken after $6 \mathrm{~h}$ of extraction approaches that of a synthetic surfactant (SS). The appropriate viscous force for deinking flotation was found to be 1.5-2.0 $\times 10^{-4} \mathrm{mg} / \mathrm{mm} \mathrm{s}^{2}$ when the synthetic surfactant is used compared to $1.0-1.5 \times 10^{-4} \mathrm{mg} / \mathrm{mm} \mathrm{s}^{2}$ for FAMC. The higher intermolecular bonding strength in the synthetic surfactant-ink particle system requires higher viscous force.
\end{abstract}

\section{Introduction}

Deinking before the recycling of paper is a very demanding process from an environmental standpoint. Most deinking processes use harsh, synthetic chemicals that may pose a risk to the environment if not properly handled and disposed of. Studies regarding chemical deinking processes have been reported and summarized [1-4]. Enzymatic deinking has also been reported for non-impact-printed Mixed Office Waste (MOW) and photocopy paper [5], for fresh and aged newspaper [6], and for laser-printed office waste paper [7]. Use of nonionic surfactants that consist of block copolymers in deinking flotation for photocopying and laser-printed paper has also been reported [8].

The use of anionic, cationic, and nonionic surfactants without any additional chemical additives in deinking flotation has also been studied. Surfactants with different ionic properties require suitable $\mathrm{pH}$ environments that differ depending on the chemical nature of the surfactant. The use of the nonionic surfactant 2-octanol in pulping and flotation stages produces deinked pulp with the highest brightness. The potential achievable brightness is $86 \%$ ISO from a feed with a brightness of $44 \%$ ISO. Surfactants with longer carbon chains typically produce better results than those with shorter chains [9].

The use of harmful chemicals and nonenvironmentally friendly surfactants poses a potential risk to the environment. Synthetic surfactants are mostly produced from biodegradable fatty acids or fatty alcohols extracted from plant seeds, animal bones, or petrochemical products. When petrochemical products are used as the raw material for surfactants, side products such as dioxin, which has negative environmental consequences, might be produced. Most fatty acids extracted from the seed oil of plants have carbon chains ranging from $\mathrm{C}_{12}$ to $\mathrm{C}_{18}$ which can be either saturated or unsaturated $[10,11]$.

Natural surfactants for deinking, either in repulping or in flotation, may consist of both saturated and unsaturated fatty acids. The effectiveness and function of natural surfactants are highly influenced by the contents of saturated and unsaturated hydrocarbons in the fatty acid mixture. Double bonds and the length of hydrocarbon chains play an important role 
in deinking flotation. As the length of hydrocarbon chain increases, so do van der Waals interactions between the chains of adjacent molecules which bring these molecules closer to each other, aiding in the deinking process [12].

Another parameter that should be considered is the hydrophilic-lipophilic balance (HLB) value. Surfactants with high HLB values are favorable for cellulase activity, whereas those with low HLB values are favorable for ink removal [13]. The HLB value of a surfactant is closely related to its structure: the longer the hydrocarbon chain and the higher the amount of unsaturation, the better the performance of the surfactant for deinking flotation [9]. This is due to stronger intermolecular forces between the surfactant and ink with unstable electrons in the double bond promoting interaction with the polar regions of the ink molecules.

Extraction (Soxhlet extraction or maceration) can determine the composition of fatty acids obtained from the seeds of plants. Soxhlet extraction is performed primarily with heat treatment and maceration is performed only by soaking without heating. The composition of fatty acids obtained from both methods is different, with Soxhlet extraction producing higher amounts of unsaturated and polyunsaturated fatty acids (PUFA) than maceration [14]. Temperature and extraction times in the Soxhlet extraction of nannochloropsisoculata (microalga oil) significantly affect the omega-3 eicosapentaenoic acid (omega-3 EPA) content. The amount of omega-3 decreases sharply as extraction proceeds and temperature is raised [15]. Research into the refining process of soya bean oil indicates that temperatures higher than $250^{\circ} \mathrm{C}$ and refining time longer than $2 \mathrm{~h}$ lead to quality defects such as loss of stability, increased viscosity, darkening, and chemical changes reflected in reduction of the iodine value (loss of unsaturation) and increase in free fatty acids [16].

Fatty acids from plant seeds can be used as natural surfactants $[12,17]$ and fatty acids present in the seed oil of Morinda citrifolia L. are of the long-chain polyunsaturated type. They are suitable for use as natural surfactants for deinking flotation because the lipophilic part of their structure has high intermolecular interactions potential with oil-based ink. However, data on these types of fatty acids are very limited. Therefore, the purpose of this research is to elucidate the main constituent of fatty acids from the seed oil of Morinda citrifolia L. responsible for the performance of deinking flotation.

\section{Material and Methods}

2.1. Materials. The materials used in this experiment include seeds of ripe Morinda citrifolia L. fruits, n-hexane, 1.0\% $\mathrm{H}_{2} \mathrm{SO}_{4}$, methanol, $\mathrm{NaHCO}_{3}$, old newspaper grade 8, sodium lauryl sulfate (SLS), papyrase enzyme (which is a specially developed hemicelluloses enzyme for modification of cellulosic fibers and removal of ink and dirt from waste paper), and a synthetic surfactant.

2.2. FAMC Preparation. The seeds of ripe Morinda citrifolia L. were air-dried and powdered using a stone mill. The seed powder was then subjected to Soxhlet extraction using nhexane as the solvent. The extraction process was performed for $4,5,6,7$, or $8 \mathrm{~h}$ in the Soxhlet extractor and then concentrated using a rotary vacuum evaporator (IKA@RV 10 digital). This concentrated the product, which was denoted as FAMC and used as the surfactant in flotation deinking. The FAMC composition was determined using the following procedure: small portions of FAMC of approximately $50 \mathrm{mg}$ were esterified by adding $4.8 \mathrm{~mL}$ of $1.0 \% \mathrm{H}_{2} \mathrm{SO}_{4}$ in methanol, refluxed for $60 \mathrm{~min}$ at $50^{\circ} \mathrm{C}$, and then cooled and neutralized with $\mathrm{NaHCO}_{3}$ until a pH of 7 was reached. After two phases of organic matter and water were established, the organic phase was analyzed using gas chromatography-mass spectrometry (GC-MS) QP 2010 S.

2.3. Deinking Flotation. Old newspaper (ONP) was torn into small pieces and $50 \mathrm{~g}$ of ONP was disintegrated in $0.9 \mathrm{~L}$ of water for $10 \mathrm{~min}$ using a mixer at $2000 \mathrm{rpm}$. This process was performed at $30^{\circ} \mathrm{C}$ and $\mathrm{pH} 7$ and $4-5 \%$ consistency. The pulp was taken ( $35 \mathrm{~g}$ o.d.) and $1.0 \%$ papyrase enzyme was added to initiate ink particle detachment. SLS (0.6\%) and 0.15\% FAMC or synthetic surfactant were mixed well and poured into a flotation tank with a volume of $18 \mathrm{~L}$ that had been filled $70 \%$ with water as shown in Figure 1.

Flotation was carried out for $10 \mathrm{~min}$ at $\mathrm{pH} 7$ and a temperature of $30^{\circ} \mathrm{C}$ at a constant air flow rate of $10 \mathrm{~L} / \mathrm{min}$ through the orifice at the bottom of the flotation tank, as monitored by a flow indicator (FI), and a constant air pressure of $1 \mathrm{~kg} / \mathrm{cm}^{2}$, monitored by a pressure indicator (PI). Various air flow rates were also used to determine the effect of viscous flow on deinking performance. The ink particles that accumulated on the bubble surfaces (as froths) were scraped from the upper part of the flotation tank. The deinked pulp was discharged through the outlet valve at the bottom of the flotation tank. The pulp was collected and formed into a sheet (Tappi T 205 sp-02). The sheet was then air-dried and measured for brightness at $457 \mathrm{~nm}$ (Tappi T 452) and effective residual ink concentration (ERIC) at $950 \mathrm{~nm}$ (Tappi T 567 om-04) using a Technidyne Color Touch 2 model ISO.

\section{Results and Discussion}

The effect of Soxhlet extraction time on the composition of fatty acids from seeds of Morinda citrifolia $\mathrm{L}$. is presented in Figure 2.

Figure 2 shows that extraction times $6 \mathrm{~h}$ onwards produce abundant amounts of long polyunsaturated fatty acids methyl ester $\mathrm{C}_{19} \mathrm{H}_{34} \mathrm{O}_{2}(\mathrm{C} 19: 2)$ and $\mathrm{C}_{21} \mathrm{H}_{38} \mathrm{O}_{2}(\mathrm{C} 21: 2)$ as the primary products. Before $6 \mathrm{~h}$, the long-chain hydrocarbons are mixed with significant amounts of short unsaturated fatty acids (short UFA) and short saturated fatty acids (short SFAs). At the $4 \mathrm{~h}$ point, the FAMC is dominated by short UFA and SFA. FAMC produced $7 \mathrm{~h}$ onwards contains large amounts of polyunsaturated fatty acids (PUFA). An increasing amount of polysaturated fatty acids (PSFA) of C16:0 and C17:0 were also found to have been produced at 7 and $8 \mathrm{~h}$. This FAMC also contains short polyunsaturated and saturated fatty acids in limited amounts. When extraction is performed, the lightest fatty acids are most easily extracted and elute first, whereas the heaviest fatty acids are extracted in the last fractions at times longer than $6 \mathrm{~h}$. This finding agrees with previous 


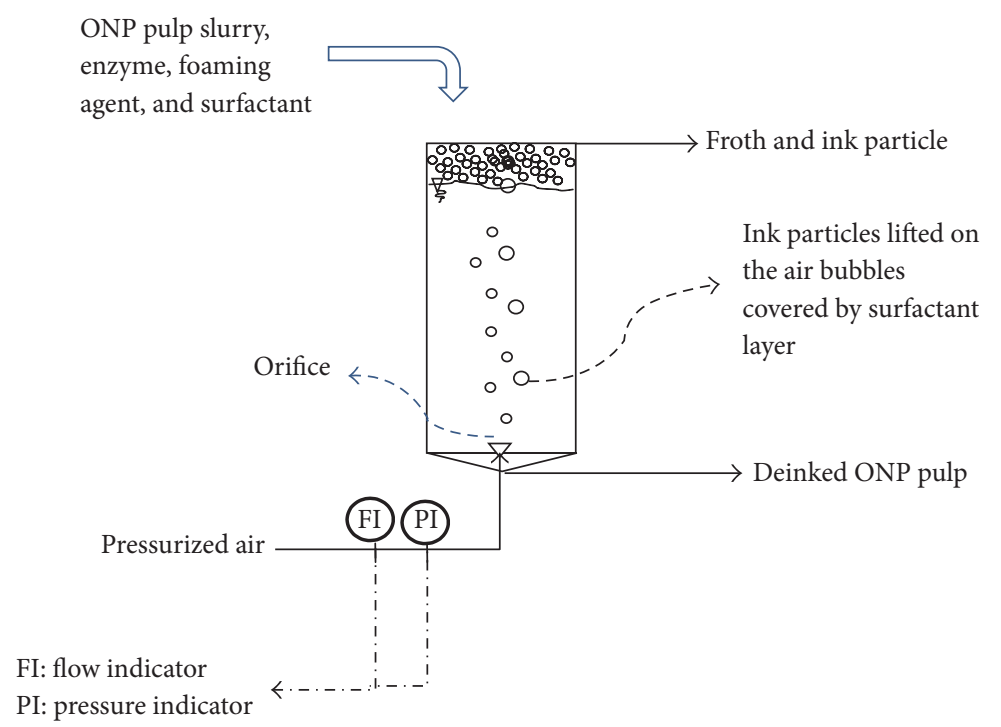

FIGURE 1: Schematic diagram of a flotation tank arrangement.

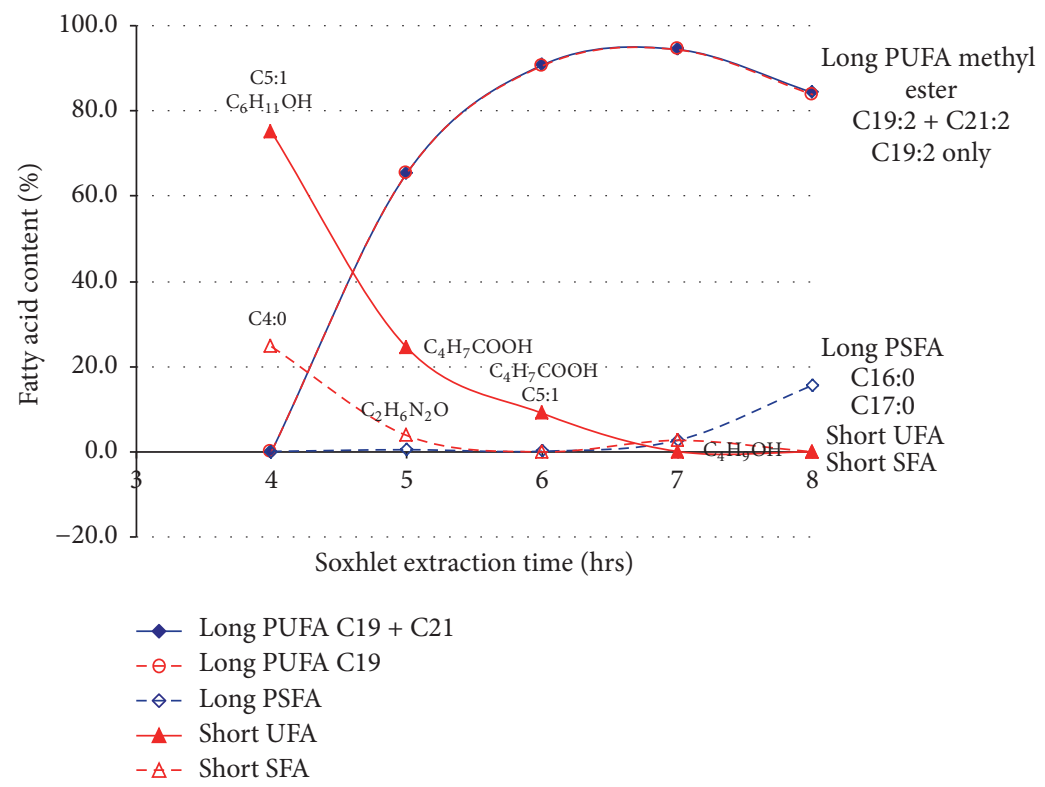

FIGURE 2: Fatty acids composition of FAMC over $8 \mathrm{~h}$ of Soxhlet extraction procedure determined by GC-MS.

research concerning the effect of Soxhlet extraction and maceration on fatty acid composition [14] and concerning the effect of extraction time on omega-3 content [15].

Changes from the natural composition of fatty acids in Morinda citrifolia L. seeds may occur during the extraction process, such as cracking of long-chain hydrocarbons and polymerization of short-chain hydrocarbons into long saturated hydrocarbons. Long saturated hydrocarbons can be produced if fatty acids have been exposed to hightemperature surfaces such as the bottom of an extraction flask. This explains the findings in previous studies of soya bean oil that high temperature and longer refining times lead to the reduction of unsaturation [16]. These results also indicate that different methods of extraction produce different compositions of FAMC.

Seeds of Morinda citrifolia L. contains fatty acids of several molecular structures. Figure 2 confirms that the extraction time affects the extraction results and that $6 \mathrm{~h}$ is the optimal time to produce high concentrations of longchain polyunsaturated fatty acids (PUFA). Extraction time less than $6 \mathrm{~h}$ resulted in mostly short-chain fatty acids and more than $6 \mathrm{~h}$ yielded long-chain PUFA with small amounts of PSFA that reduce the deinking flotation performance of the surfactant. The results from the use of FAMC as a surfactant for deinking flotation are presented in Figure 3. Figure 3(a) shows the brightness and Figure 3(b) shows the 


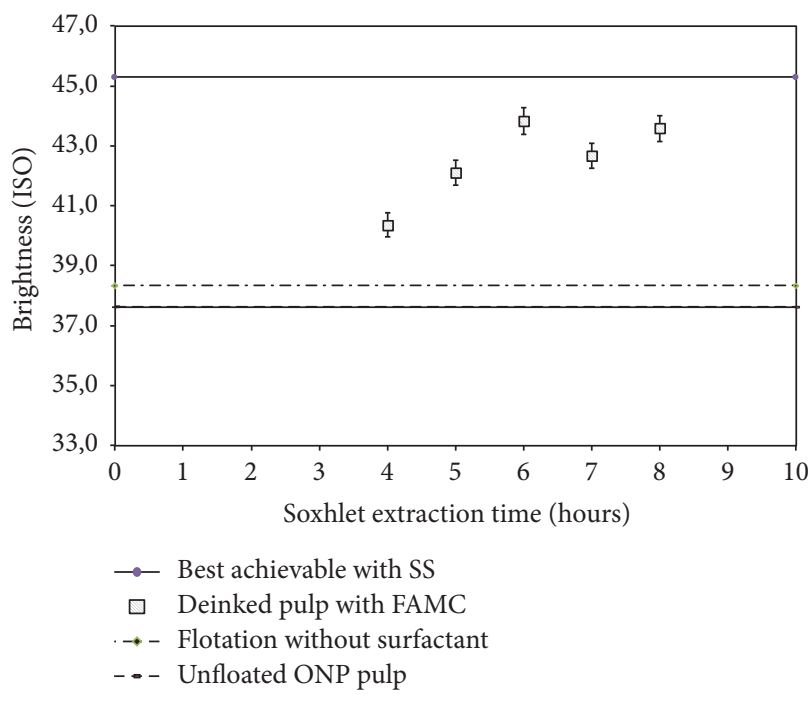

(a)

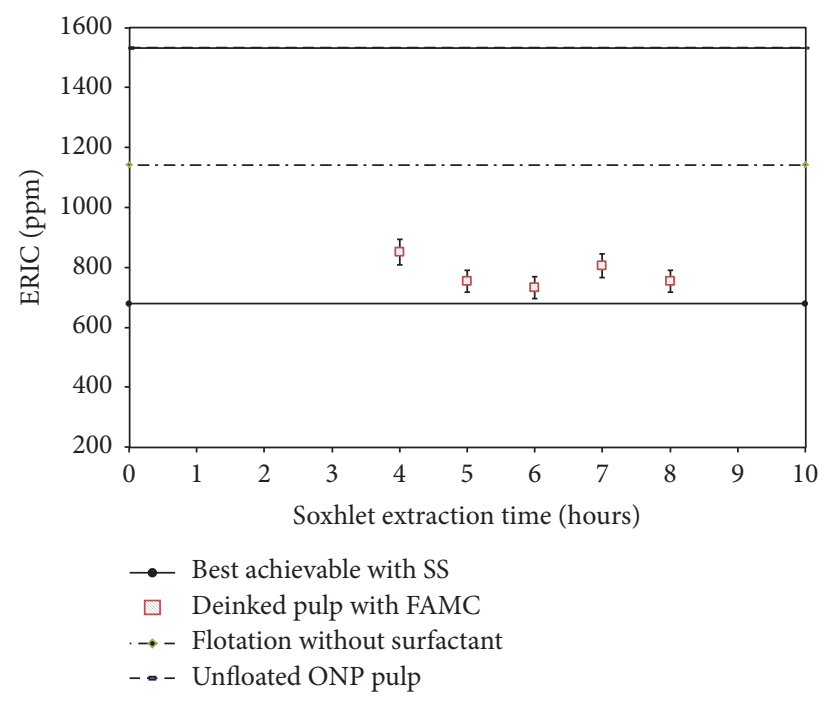

(b)

FIGURE 3: (a) Brightness achievement; (b) ERIC achievement of deinked pulp after deinking flotation with FAMC isolated at different Soxhlet extraction times.

ERIC of deinked pulp after flotation with FAMC for different extraction times.

FAMC isolated at $6 \mathrm{~h}$ gave the best performance in deinking flotation of the fractions tested. The best achievable brightness and ERIC of deinked pulp using FAMC approached that of a synthetic surfactant. When comparing the deinking power of the two methods, it seems that the deinking power of FAMC from $6 \mathrm{~h}$ is similar to that of synthetic surfactants. This correlates with the chain length of PUFA. As the chain length increases, van der Waals interactions between the chains of adjacent molecules (between PUFA itself or between PUFA and fatty esters of ink particles) increase, bringing these molecules closer to each other and facilitating removal via mechanical processes. This condition agrees with another study [12].

Besides the length of hydrocarbon chain and its saturation status, the balance between the hydrophilic and lipophilic properties (HLB value) of the surfactant also plays an important role in the achievement of effective deinking flotation. Through slight modifications, especially of the balance of hydrophobic and hydrophilic characters, the deinking power of FAMC can be improved and FAMC can be modified to have good miscibility with both water and ink phases [9]. The abundance of long hydrocarbon chains with double bonds (polyunsaturation) is the most important factor to create hydrophobic character for the surfactant. On the other hand, the ester functional group $\left(\mathrm{C}-\mathrm{OO}-\mathrm{CH}_{3}\right)$ contributes to the hydrophilic character of the surfactant molecules.

Figures 2 and 3 suggest that the presence of poly unsaturated fatty acids C19:2 and C21:2 are important for the high deinking performance of FAMC. This observation is consistent with the results of other studies that showed cooperative interactions among molecules at interfaces in various technological processes [12]. Longer chains and increased unsaturation resulted in better performance of surfactant for deinking flotation.
The main chemicals used in this study are a synthetic surfactant, FAMC, and black printing ink that mostly consists of carbon black and fatty ester. The molecular structures of these compounds are listed in Figure 4.

Based on the molecular structure of the compounds that constitute FAMC and the synthetic surfactant, their interaction with ink particles can be explained by their dual hydrophobic and hydrophilic nature, as shown in detail in Figure 5. The double bond structure of PUFA in FAMC undergoes intermolecular bonding with the fatty acids or fatty esters of ink molecules. In the case of the synthetic surfactant, intermolecular bonding does occur not only in the PUFA region of the molecule but also in the polyoxyethylene $\left([\mathrm{EO}]_{n}\right)$ part of the synthetic surfactant, in the form of hydrogen bonding.

In interactions with water molecules, the synthetic surfactant shows good miscibility due to the nonbonding electron pairs of oxygen in $[\mathrm{EO}]_{n}$. In addition, it has an $\mathrm{O}-\mathrm{SO}_{3}$ group that facilitates hydrogen bonding with water molecules. According to Mayeli and Talaeipour, surfactants with a high HLB value are favorable for improved cellulase activity and those with a low HLB value are favorable for ink removal [13]. FAMC has a low HLB value; thus, it can better penetrate oil phases. This is due to the fact that its hydrophilic character depends solely on the carboxylic structure of the fatty acid because no polarity-inducing modifications have been made. Therefore, FAMC has good characteristics for ink removal but has difficulties penetrating the aqueous phase (Figure 5). These compounds are designed primarily to facilitate deinking flotation, as shown in Figure 3.

The hydrophobic part of the FAMC, synthetic surfactant, and foaming agent play an important role in facilitating interaction with ink particles. The double bonds in the synthetic surfactant and in FAMC, wherein the electrons are more unstable, lend them a tendency to form hydrogen bonds with oxygen atoms and hydrogen atoms on ink molecules. 

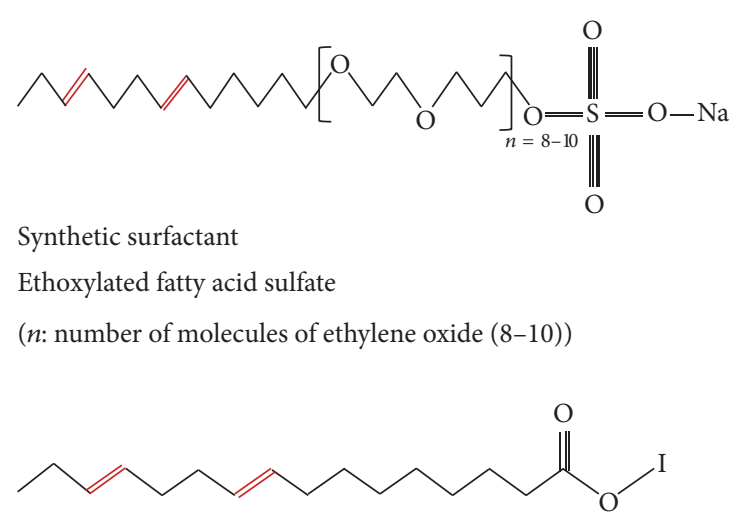

FAMC main constituent
Major: PUFA C19:2 and C21:2
Minor: PSFA C16:0 and C17:0

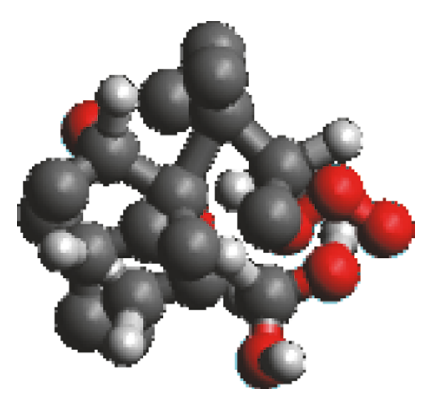

Black ink composition

Main: carbon black

Others: fatty acid and fatty ester

FIGURE 4: Molecular structures of materials used in this experiment.

The oxygen atoms in the ethoxylated part of the fatty acid derivative of the synthetic surfactant had a greater tendency to form hydrogen bonds with ink molecules.

Figure 6 shows viscous forces created by the bubbling of air through orifices during deinking flotation in the flotation and jet zones. The bubbles in the flotation zone lift and separate the detached ink, whereas the bubbles in the jet zone detach ink from the paper fiber surface. The viscous forces shown in Figure 6 were estimated from Reynolds number formula. Understanding these forces is important in order to achieve better deinking results as they are responsible for ink liberation and dispersion. High viscous force in the jet zone is important for ink detachment: the higher the viscous force, the better the ink detachment. In the flotation zone, high viscous force does not mean better flotation since bubbles and ink aggregates are more likely to be broken under a higher viscous force. This phenomenon is demonstrated in Figure 7.

Figure 7 clearly shows that the brightness and ERIC of paper processed by deinking flotation is strongly affected by the viscous force. The bubbles in the flotation zone created from the orifice of D40 give the best results with regard to brightness and ERIC. In addition to the surfactants, viscous forces play an important role in determining the extent of intermolecular bonding between surfactant and ink particles.
In the synthetic surfactant system, the best result is obtained for bubbles created at viscous forces between 1.5 and $2.0 \times$ $10^{-4} \mathrm{mg} / \mathrm{mm} \mathrm{s}^{2}$, while, in the FAMC system, the best result is obtained at viscous forces of $1.0-1.5 \times 10^{-4} \mathrm{mg} / \mathrm{mm} \mathrm{s}^{2}$. This result can be explained by the stronger intermolecular bonding in the synthetic surfactant system than in the FAMC system. These viscous forces should not be exceeded to keep the ink aggregate intact on the bubble.

When these viscous forces are exceeded, the intermolecular bonding between surfactant (or FAMC) and ink particles will be broken and the deinking flotation process will result in less than optimal brightness and ERIC value. This is also true for bubbles created using other orifice diameters. Therefore, it can be concluded that the intermolecular bonding in bubbleink aggregates in the synthetic surfactant system is slightly stronger than that in the FAMC system.

\section{Conclusions}

The seed oil of Morinda citrifolia L. contains major components of unsaturated fatty acids, specifically $\mathrm{C}_{19} \mathrm{H}_{34} \mathrm{O}_{2}$ and $\mathrm{C}_{21} \mathrm{H}_{38} \mathrm{O}_{2}$, which contain two double bonds in their structures. Compounds containing these features, which are necessary for the hydrophobic character of ideal surfactants, 


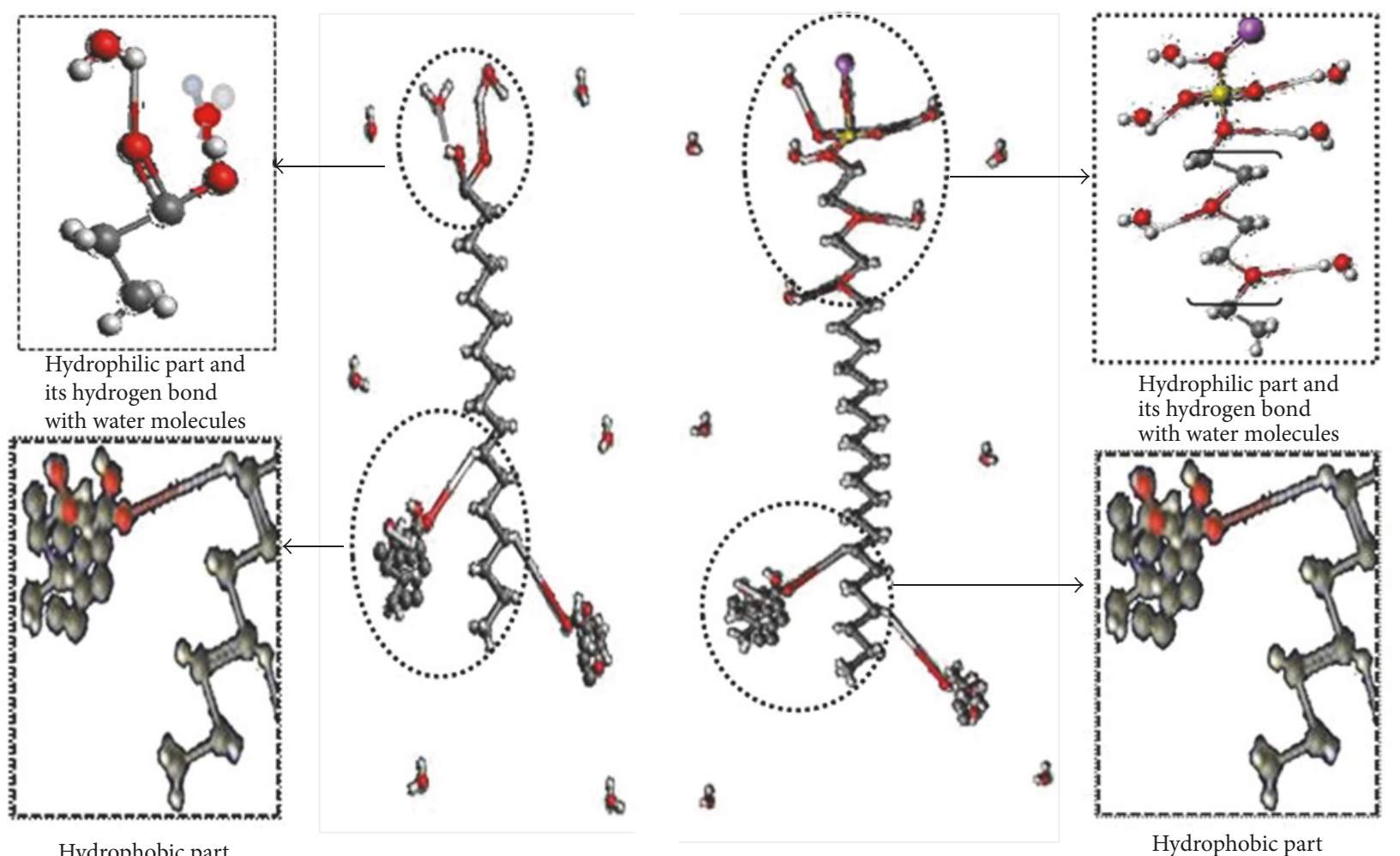

FAMC

Synthetic surfactant

FIGURE 5: Stick-and-ball representations of the theoretical interactions between ink particle, FAMC, and synthetic surfactant molecules.

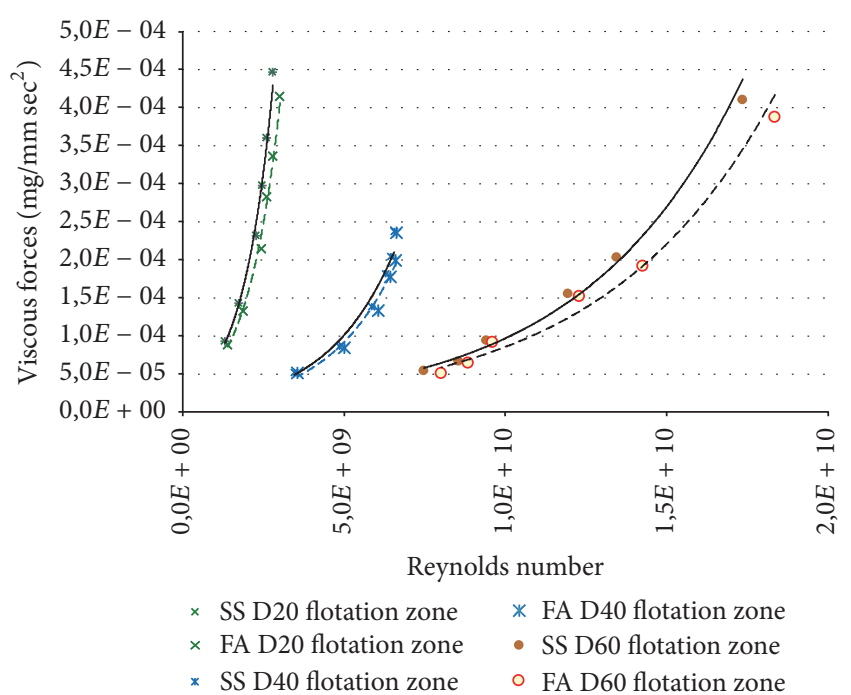

(a)

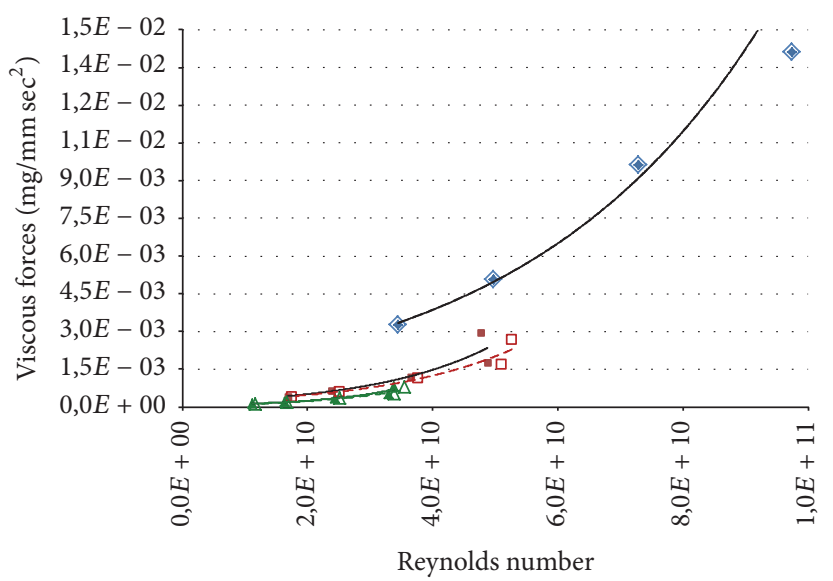

$\begin{array}{ll}\text { - SS D20 jet zone } & \text { - SS D40 jet zone } \\ \diamond \text { FA D20 jet zone } & \square \text { FA D40 jet zone } \\ \Delta \text { SS D60 jet zone } & \triangle \text { FA D60 jet zone }\end{array}$

(b)

FIGURE 6: Viscous forces as a function of Reynolds number of bubbles in flotation tank. (a) Viscous forces at the flotation zone and (b) viscous forces at the jet zone. 

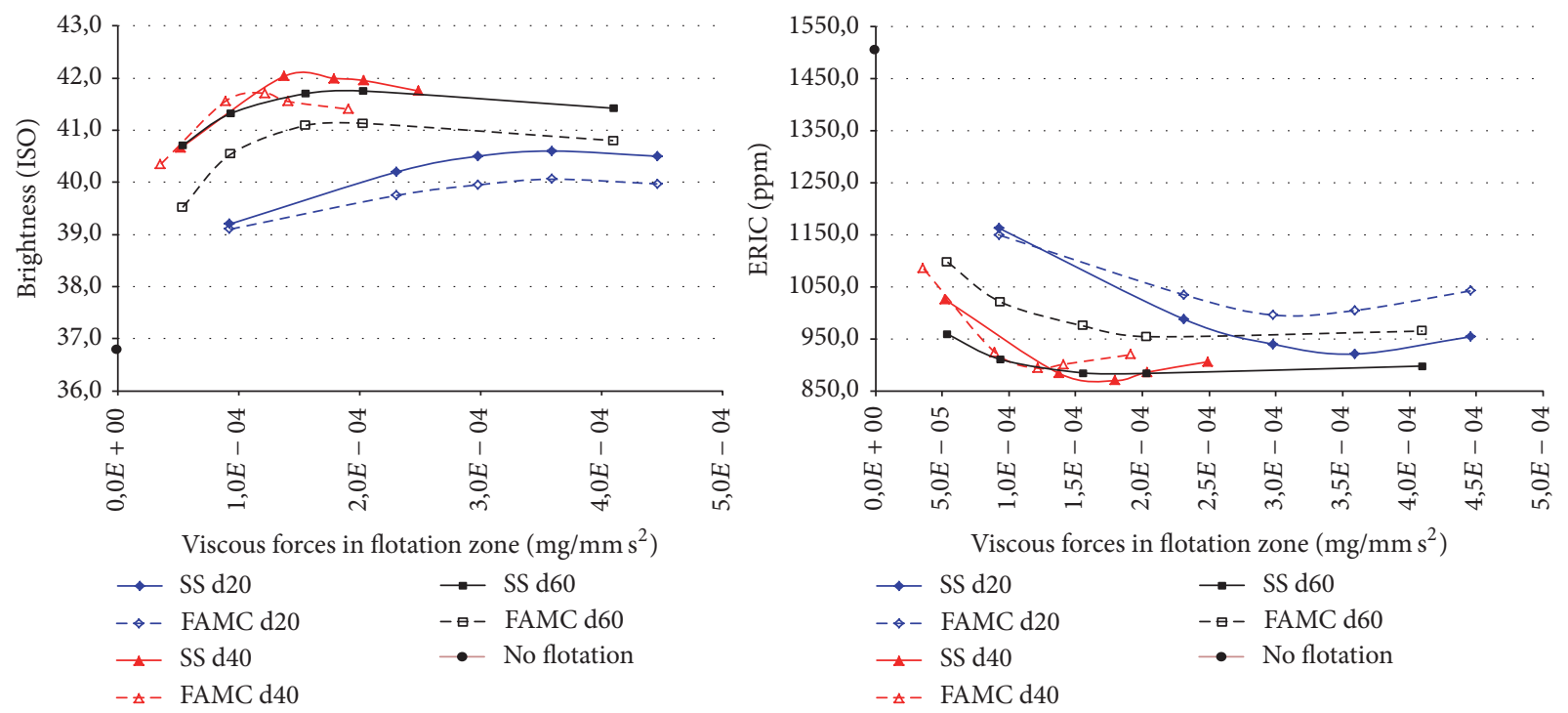

FIGURE 7: Effect of viscous force in the flotation zone on the resulting brightness and ERIC of the deinked pulp.

were isolated from the $6 \mathrm{~h}$ point of extraction. This fraction gave the most suitable esters for deinking surfactants to promote ink removal. The $6 \mathrm{~h}$ fraction contained the highest proportion of PUFA (C19:2) with two double bonds among all other FAMC products.

The long hydrocarbon chain of PUFA in FAMC promotes strong interaction with the ink particle. The double bonds in the structure of PUFA induce intermolecular bonding with the fatty acids or esters of the ink molecules.

The intermolecular bonding between the synthetic surfactant and ink is stronger than that of FAMC. Therefore the optimal viscous force in the synthetic surfactant system is higher than that in the FAMC system. An overly high viscous force causes the destruction of the bubble-ink aggregate, reducing deinking performance.

\section{Conflicts of Interest}

The authors declare that they have no conflicts of interest.

\section{Acknowledgments}

The authors are grateful for the financial support provided by the Indonesian Directorate General of Higher Education (DGHE or DIKTI), Grant no. 1014/UN10.14/KU/2013. The authors are also grateful to PT KAO Indonesia Branch Surabaya for providing papyrase enzyme and the synthetic surfactant and to Darono Wikanaji, M. Eng., Pulp and Paper Technology Lecturer and Consultant for helpful discussions and valuable suggestions.

\section{References}

[1] K. Stack, K. J. Tria, and D. E. Richardson, "Ink detachment and redeposition in alkali flotation deinking systems," Appita Journal, vol. 58, no. 4, pp. 297-301, 2005.

[2] C. P. J. Bennington and M. H. Wang, "A kinetic model of ink detachment in the repulper," Journal of Pulp Paper Science, vol. 27, no. 10, pp. 347-352, 2001.
[3] C. A. Costa and J. Rubio, "Deinking flotation: influence of calcium soap and surface-active substances," Minerals Engineering, vol. 18, no. 1, pp. 59-64, 2005.

[4] N. Luangsa-Ard, O. Khampan, and S. Chaiareekij, "Comparisons between flotation deinking abilities of newsprint paper by using enzyme and chemicals," Journal of Chemistry and Chemical Engineering, vol. 6, no. 9, pp. 832-837, 2012.

[5] H. Pala, M. Mota, and F. M. Gama, "Enzymatic versus chemical deinking of non-impact ink printed paper," Journal of Biotechnology, vol. 108, no. 1, pp. 79-89, 2004.

[6] X. Zhang, S. Renaud, and M. Paice, "Cellulase deinking of fresh and aged recycled newsprint/magazines (ONP/OMG)," Enzyme and Microbial Technology, vol. 43, no. 2, pp. 103-108, 2008.

[7] C. K. Lee, I. Darah, and C. O. Ibrahim, "Enzymatic deinking of laser printed office waste papers: some governing parameters on deinking efficiency," Bioresource Technology, vol. 98, no. 8, pp. 1684-1689, 2007.

[8] T. Moon and R. Nagarajan, "Deinking xerographic and laserprinted paper using block copolymers," Colloids and Surfaces A: Physicochemical and Engineering Aspects, vol. 132, no. 2-3, pp. 275-288, 1998.

[9] M. A. Khalek, "Performance of different surfactants in deinking flotation process," Elixir International Journal of Applied Chemistry, vol. 46, pp. 8147-8151, 2012.

[10] D. Moigradean, M. A. Poiana, L. M. Alda, and I. Gogoasa, "Quantitative identification of fatty acid from walnut and coconut oil using GC-MS method," Journal of Agroalimentary Processes and Technologies, vol. 19, no. 4, pp. 459-463, 2013.

[11] V. Kostik, S. Memeti, and B. Bauer, "Fatty acid composition of edible oils and fats," Journal of Hygienic Engineering and Design: Food Production and Processing, vol. 4, pp. 112-116, 2013.

[12] J. R. Kanicky, A. F. Poniatowski, N. R. Mehta, and D. O. Shah, "Cooperativity among molecules at interfaces in relation to various technological processes: effect of chain length on the pKa of fatty acid salt solutions," Langmuir, vol. 16, no. 1, pp. 172177,2000

[13] N. Mayeli and M. Talaeipour, "Effect of different HLB value and enzymatic treatment on the properties of old newspaper deinked pulp," Bioresources, vol. 5, no. 4, pp. 2520-2534, 2010. 
[14] K. R. Sridhar and S. J. Shreelalitha, "Composition of fatty acids of the lipids extracted from seeds of sesbaniabispinosa grown on the Indian Coastal Sand Dunes," Current Nutrition \& Food Science, vol. 12, no. 1, pp. 50-55, 2016.

[15] O. K. Topuz, A. Kaya, and A. C. Alp, "Effect of extraction variables on the omega-3 eicosapentaenoic (EPA) content of (nannochloropsisoculata) microalga oil," Scientifics Bulletin Series F. Biotechnologies, vol. 20, no. 16, pp. 172-177, 2016.

[16] M. Jawad, S. P. Kochhar, and B. J. F. Hudson, "Quality characteristics of physically refined soyabean oil: effects of pre-treatment and processing time and temperature," International Journal of Food Science \& Technology, vol. 18, no. 3, pp. 353-360, 1983.

[17] A. Lassus, Recycled Fiber and Deinking, Papermaking Science and Technology, chapter 8, Tappi Press/Fapet Oy, Helsinki, Finland, Europe, 2000. 


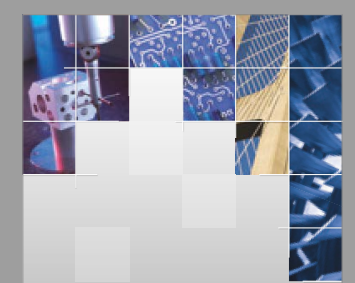

\section{Enfincering}
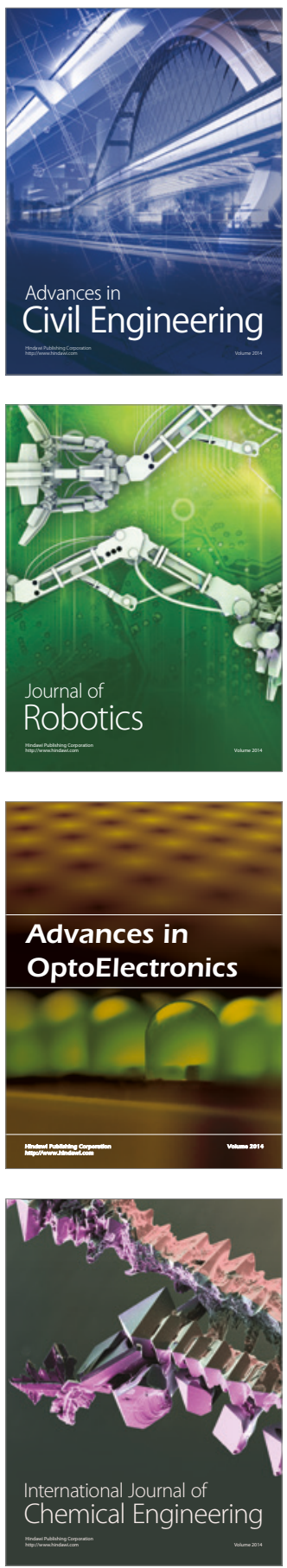

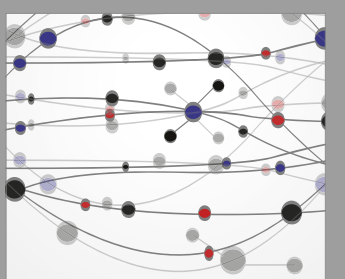

The Scientific World Journal

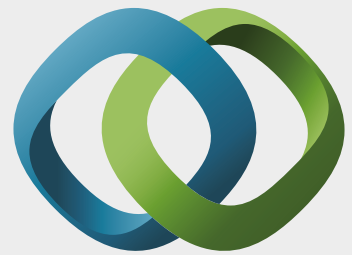

\section{Hindawi}

Submit your manuscripts at

https://www.hindawi.com
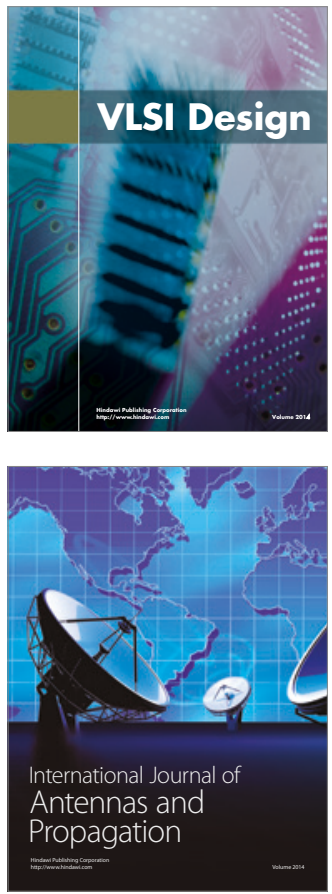

\section{Rotating}

Machinery
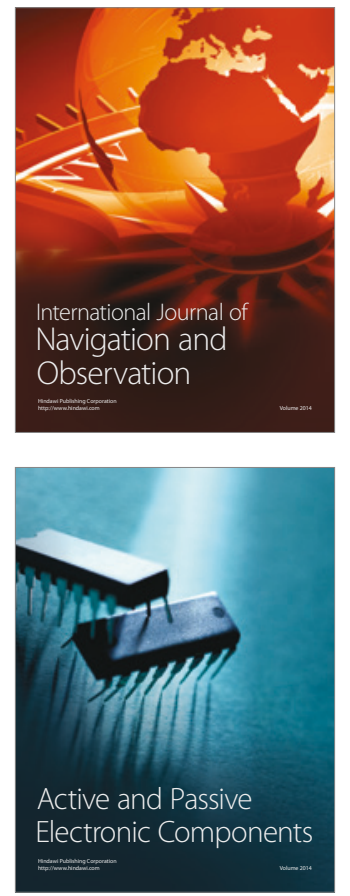
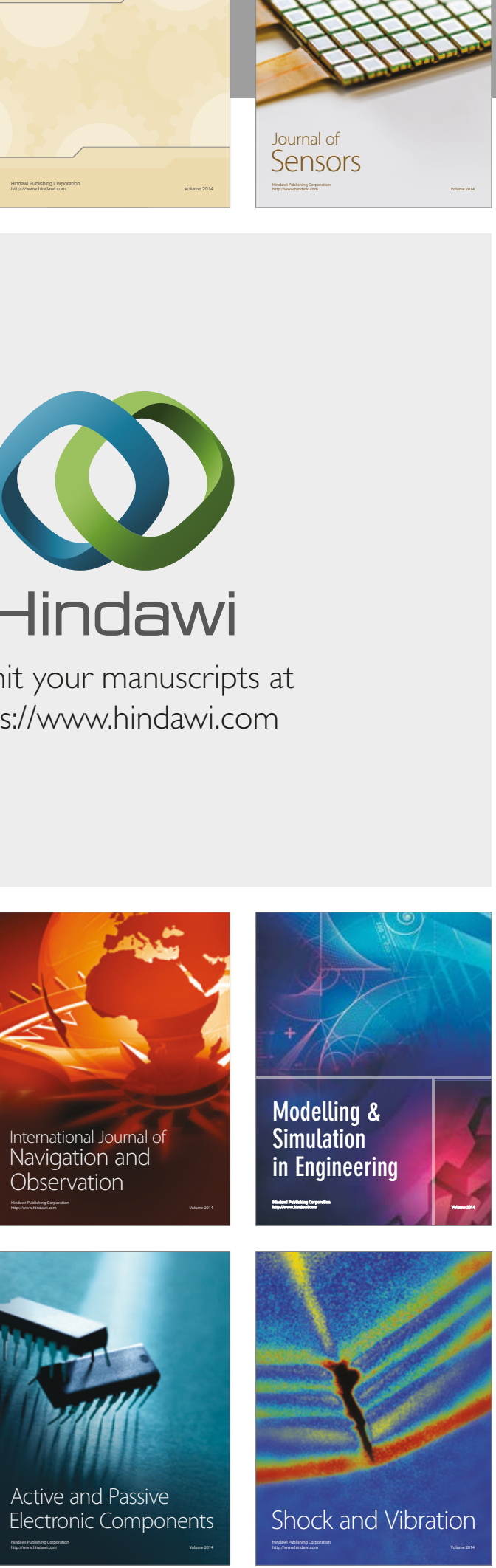
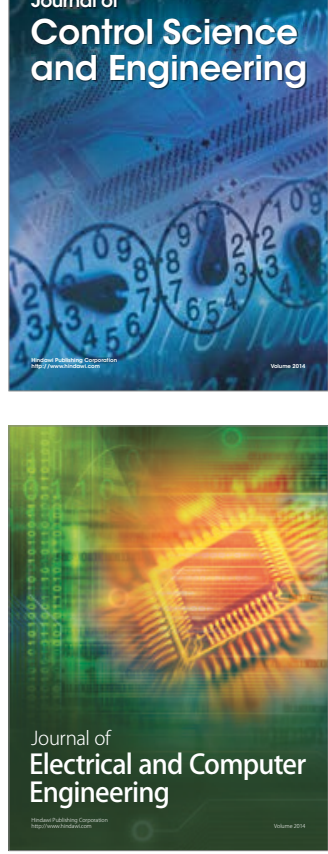

Distributed

Journal of

Control Science

and Engineering
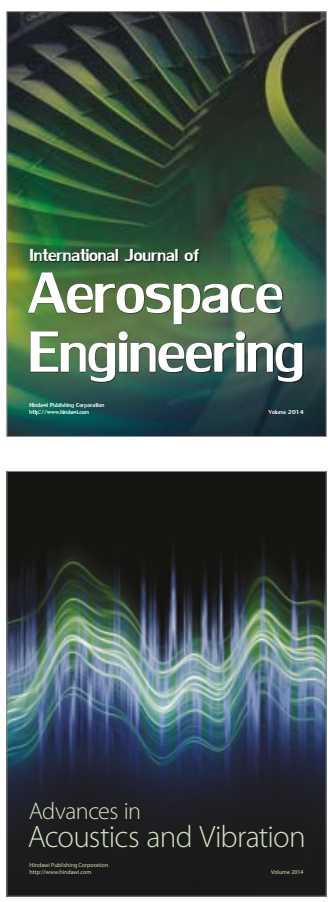

Sensor Networks 